\title{
Portuguese Water Dog
}

National Cancer Institute

\section{Source}

National Cancer Institute. Portuguese Water Dog. NCI Thesaurus. Code C53774.

The Portuguese Water dog is a hardy, muscular, medium-sized dog. The single-layered, non-shedding, virtually hypo-allerg enic coat comes in black, white or brown, parti-color (white with dark spots), black or brown with white markings, or even silver fox or gray. The coat varies from flat, wavy, shiny type to a thick, open curl, to a tight curl. It has more webbing between the toes than many other breeds, which aids in swimming. The heart-shaped ears hang down beside the head. Height: 17-22 inches $(43-57 \mathrm{~cm}$.) Weight: $35-55$ pounds (16-25 kg.) 